\title{
Fixed Or Variable Rate Choice In The Commercial Bank Business Loan Market
}

Manoj Athavale (E-mail: athavale@bsu.edu), Ball State University Robert O. Edmister (E-mail: bedmister@olemiss.edu), University of Mississippi

\begin{abstract}
We study the choice available to business borrowers and lenders between fixed rate and variable rate bank loans. Unlike previous studies that examine residential mortgage loans, this analysis examines commercial and industrial loans. Business loans differ in attributes from mortgage loans and hence provide an opportunity to test determinants of the mortgage loan choice decision for other loan types. The diversity of business loans also permits tests of any effect which lender size and borrower size may have on the choice decision. Using a continuous index of preferences for the variable rate commercial loan, we find that the determinants of the business loan choice decision are different from the determinants of the mortgage loan choice decision. In contrast to prior research, we find strong evidence contradicting the proposition that variable rate loans are merely a response to high and variable interest rates. Further, this the first study to reveal size as a determinant of loan choice. Larger banks and larger borrowers have a greater preference for variable rate loans. Our results combined with the consolidation occurring among banks leads to the conclusion that the observed shift to variable rate bank loans is not transitory, and poses a significant risk for businesses with asset returns uncorrelated with short-term loan rates.
\end{abstract}

\subsection{Introduction}

V

ariable rate loans are contracts that adjust the interest rate concurrently with an open market index. Other contract terms, including repayment, remain independent of interest rate. The variable rate contract commits the business to an uncertain future interest expense and transfers interest rate risk from the lender to the borrower. The alternative choice, a fixed rate contract, has exactly the opposite effect on banks and businesses. Thus, the interesting issues arising from the choice between fixed and variable rate loans is discerning the determinants of this choice decision. However, previous empirical tests of the determinants of the fixed rate versus variable rate loan decision have only analyzed mortgage loans. The purpose of this paper is to model and test factors that determine the choice for variable rate business loans. Business loans differ from mortgage loans with respect to maturity term, repayment terms, purpose, collateral, and securitization. Mortgage loans are for long periods, often ranging up to thirty years while business loans extended by banks are for shorter periods. Mortgage loans are generally amortized over the life of the loan while business loans often remain outstanding for the initial amount. The purpose of the loan is fairly standard in the case of mortgage loans but may vary widely for business loans, introducing greater complexity in the valuation of collateral. In the absence of standardized contracts, the scope for securitization of business loans and the creation of an efficient secondary market is limited. These and other differences in the characteristics of mortgage and business contracts might result in differential risk assessments and may influence the fixed rate and variable rate loan choice decision.

Participants in financial markets do not all have the same ability to accept or transfer risk and this might influence their loan choice decision, for example, Berkovec, Kogut and Nothaft (2001) find that the market for

Readers with comments or questions are encouraged to contact the authors via email. 
variable rate "jumbo" origination is two to three times the size of the "conforming" market, and Balsam and Kim (2001) find that it is the large firms that are more likely to engage in interest rate swaps to hedge against interest rate risk. We therefore test for segmentation within the market for variable rate business loans by considering bank size and loan size as determinants of the fixed and variable rate business loan choice decision.

The popularity of the variable rate mortgage loans has been attributed to the high and volatile interest rates of the late 1970s and early 1980s and the regulatory changes of 1981, which permitted variable rate mortgage loans. Brueckner and Follain (1988) observe that the "adjustable rate mortgages moved from near obscurity in 1981 to become the dominant instrument in 1984, when two-thirds of all mortgages were adjustable rate. Almost as rapidly, they declined in importance with their market share falling to near 20 percent in June 1986." Goldberg and Heuson (1992) observed that the proportion of variable rate financing has varied greatly from less than 25 percent in June 1986 to almost 75 percent in December 1987. In comparison, variable rate business loans existed long before variable rate mortgage loans. We therefore examine the market share trend of variable rate business loans (as compared to total business loans) over time, to assess whether variable rate business loans are merely responses to volatile interest rates.

The fixed or variable rate choice decision has been studied in markets other than the residential mortgage market. For example, the credit card market (Stango (2000)), the commercial mortgage market (Dhillon, Sa-Aadu and Shilling (1996)), in the market for fixed or variable rate insurance or retirement annuities, in the context of interest rate swaps (Balsam and Kim (2001)) and prepayment and default in the derivative market for asset backed securities (Calhoun and Deng (2002)).

Our literature search revealed that this is the first paper that addresses the choice decision for business loans. Consequently, we start this paper with a review of theoretical concepts developed for mortgage loan contracts, and address the possibility that the business loan contract choice is determined by characteristics unique to corporate finance and different from an individual's mortgage loan choice decision.

\subsection{Review of Theoretical and Empirical Literature}

\subsection{The Theoretic Background}

Baesel and Biger (1980) analyzed the implications of fixed and variable rate mortgages in the context of the high inflation and interest rates of the late 1970s. They asserted that the traditional fixed rate contract could be thought of as a loan combined with a bet on inflation. In equilibrium, the lender should be indifferent between fixed and variable rate loans, so long as the contract rate is appropriate to the level of risk. Further, their analysis suggests that under competitive conditions and positive inflation risk, variable rate mortgages will be offered at a lower interest rate compared to fixed rate mortgages. While lenders may not have a preference for fixed versus indexlinked mortgages, borrowers may have a preference depending on the covariance of their income stream with inflation. Since no a priori expectations of borrower preference were possible, the solution suggested by Baesel and Biger (1980) to resolve the fixed rate and variable rate loan decision, is a flexible package offered by the lender, such that each borrower decides the proportion of fixed and variable rate financing.

The question of the optimal proportion of fixed rate and variable rate debt is a specific part of the general problem of the optimal capital structure of the firm. Agmon, Ofer and Tamir (1981) examined variable rate debt instruments as part of the determination of the optimal composition of the debt portfolio for a firm. They theorize that the payment schedule should be positively correlated with a firm's operating income. The solution suggested by Agmon, Ofer and Tamir (1981) to determine the optimal proportion of variable and fixed rate debt is a function of both market conditions and the nature of the income stream of the firm.

In commercial banking structure research, Santomero (1983) discussed the nature of fixed rate and variable rate loan contracts and stated that the uncertainty of funding costs makes the fixed rate loan increasingly less attractive to the bank as it includes both credit risk and interest rate risk in the same contract. However, if a variable rate loan is a greater credit risk than a fixed rate loan, the optimal loan portfolio balances marginal interest rate risk 
with marginal credit risk. Santomero (1983) showed that an immunized portfolio would not result in an optimal bank asset and liability structure. Smith (1987) showed that the circumstances most favorable to the selection of the variable rate instrument include a wide positive rate spread between fixed and variable rates, real income and real asset values that increased with both inflation and real interest rates, and a relatively low degree of risk aversion on the part of the borrower. In other related studies, Chang, Rhee and Wong (1995) examined the optimal mix of fixed and variable rate loans and the spread between fixed and variable loan rates. They found that the expected spread varies directly with the volatility of the funding cost, the banks degree of risk aversion and the competitive profit margin on variable rate loans.

\subsection{The Empirical Evidence}

Page and Sirmans (1984) examined reasons for differences in yield between fixed rate and variable rate mortgages sold in the conventional secondary market. The difference in the secondary market yield between fixed rate and variable rate mortgages was modeled to be a function of the default risk premium difference, the interest rate risk premium on a fixed rate mortgage, the holding period premium difference, and the options premium difference. Contrary to expectations, their results indicate that during periods when the term structure was relatively flat, the secondary market yield on adjustable rate mortgages was higher than fixed rate mortgages, suggesting that the pricing of variable rate mortgages needed to be more competitive. Dhillon, Shilling and Sirmans (1987) used a probit model to conduct an empirical test of the impact of pricing and borrower characteristics on the choice of the mortgage contract and concluded that, in general, pricing variables play a dominant role while borrower characteristics have a relatively weak influence in the mortgage choice decision. These results contradict Baesel and Biger (1980) who postulated a strong relationship between the characteristics of the borrower's income stream and preferences for fixed rate and variable rate loans. To test the characteristics of the choice decision, Brueckner and Follain (1988) constructed an econometric model of the choice between fixed and variable rate mortgages and confirmed the Dhillon, Shilling and Sirmans (1987) conclusion that borrower characteristics do not influence the mortgage choice decision. The most important variables that explained the fixed and variable loan choice decision were pricing variables: the differential between the fixed and variable rate and the level of the fixed loan rate. A higher differential between fixed and variable rates raises the probability of choosing variable rate loans. Further, for a given rate differential, the level of interest rates and the probability of choosing an adjustable rate mortgage were positively related.

By simulating the present value cost differential between fixed and variable rate mortgages, Tucker (1991) showed that the cost advantage of the adjustable rate mortgage depends on the mortgage holding period and discount rate (i.e. expectations of future interest rates). The results of this analysis indicate that, for short holding periods, all variable rate mortgage borrowers have a present value advantage; while for longer holding periods, borrowers with a low discount rate fare better with a fixed rate mortgage. At high discount rates, variable rate borrowers maintain a cost advantage over fixed rate borrowers across all holding periods. Sa-Aadu and Sirmans (1995) examined the impact of price variables and borrower characteristics on the mortgage choice decision and found that the diversity of contracts observed in the market can be viewed as a response to the presence of heterogeneous borrowers. Goldberg and Heuson (1992) used a reduced form equation to model the influence of borrower, lender and market characteristics in determining the choice between fixed and variable rate mortgage loans. They found relative cost, the level and expectations of interest rates and default risk measures to be significant in explaining the mortgage choice decision. In other related studies, Hendershott and Van Order (1987) and Cunningham and Capone (1990) stated that variable rate mortgages have a lower prepayment risk but a greater default risk, and suggested that the benefit to lenders from variable rate mortgages remains questionable, while Brewer, Jackson and Mondschean (1996) found that for some lenders, additional variable rate mortgage lending results in an increase in credit risk which dominates the decrease in interest rate risk associated with variable rate mortgages.

\subsection{Summary of Literature}

Studies of fixed and variable rate mortgages may apply to the business loan choice decision, and hence these provide a basis for the testable hypotheses. First, it is a consensus that variable rate contracts are a reaction to high and volatile interest rates. Variable rate contracts stabilize the value of the contract against changes in interest 
rates. ${ }^{1}$ Second, there is considerable empirical evidence that the level of interest rates, the spread between fixed and variable rates, expectations of future conditions and default risk, play an important role in determining the choice between fixed and variable rate loans. Third, the rate on a fixed rate loan will be higher than on a variable rate loan because the borrower is willing to pay a premium for stable payouts. At the same time, variable rate loans present lower interest rate risk and hence the lender is able to offer variable rate loans at a lower cost.

\subsection{Methodology and Data}

Consider a model of the business loan choice decision based on expected cash flows from each loan type. The present value of cash flows to the lender (from a loan extension of dollars L with fixed interest payments at the rate $\mathrm{F}$ for $\mathrm{N}$ periods) discounted at the rate $\mathrm{R}$ can be expressed as-

$$
N P V_{L, F}=-L+\frac{L^{*} F}{1+R}+\frac{L^{*} F}{(1+R)^{2}}+\frac{L^{*} F}{(1+R)^{3}}+\ldots+\frac{L^{*}(1+F)}{(1+R)^{N}}
$$

Similarly, the present value of cash flows to the lender (from a loan extension of dollars L with variable interest payments at the rate $\mathrm{V}_{\mathrm{t}=1, \mathrm{~N}}$ for $\mathrm{N}$ periods) discounted at the rate $\mathrm{R}$ can be expressed as-

$$
N P V_{L, V}=-L+\frac{L^{*} V_{1}}{1+R}+\frac{L^{*} V_{2}}{(1+R)^{2}}+\frac{L^{*} V_{3}}{(1+R)^{3}}+\ldots+\frac{L^{*}\left(1+V_{N}\right)}{(1+R)^{N}}
$$

Then, assuming $\mathrm{L}=\$ 1$,

$$
D_{L}=N P V_{L, F}-N P V_{L, V}=\frac{F-V_{1}}{1+R}+\frac{F-V_{2}}{(1+R)^{2}}+\frac{F-V_{3}}{(1+R)^{3}}+\ldots+\frac{F-V_{N}}{(1+R)^{N}}
$$

Notice that by definition, the loan rate is a function of the index to which the loan is linked and the constant markup charged on that loan relative to the index. Assuming that the interest rate applicable to any given period is determined at the start of that period, we get-

$$
\begin{aligned}
& F=P_{0}+M_{0}^{F} \\
& V_{N}=P_{N-1}+M_{0}^{V}
\end{aligned}
$$

where, $\mathrm{P}_{\mathrm{t}=0, \mathrm{~N}-1}$ is the index (for example, the prime rate) to which the loan is linked, and $\mathrm{M}^{\mathrm{F}}$ and $\mathrm{F}^{\mathrm{V}}$ is the predetermined additive markup (determined at the initiation of the contract) charged on the fixed and variable rate loan respectively. Substituting equations 4 and 5 into equation 3, it follows that-

$$
\begin{aligned}
& D_{L}=\sum_{t=1}^{N} \frac{M_{0}^{F}-M_{0}^{V}}{(1+R)^{t}}+\sum_{t=2}^{N} \frac{P_{0}}{(1+R)^{t}}-\sum_{t=2}^{N} \frac{P_{t-1}}{(1+R)^{t}} \\
& \text { Or } D_{L}=\sum_{t=1}^{N} \frac{F-V_{1}}{(1+R)^{t}}+\sum_{t=2}^{N} \frac{P_{0}}{(1+R)^{t}}-\sum_{t=2}^{N} \frac{P_{t-1}}{(1+R)^{t}}
\end{aligned}
$$

This line of reasoning suggests that the spread between fixed and variable rates at the initiation of the contract, the level of interest rates at the initiation of the contract, and loan maturity, would be significant determinants of the choice decision. We include proxies for interest rate risk and default risk in our analysis since 
the extant literature has determined that variable rate loans reduce interest rate risk but increase default risk. We test for segmentation within the market for business loans by considering the effect of originating bank size and loan size on the choice decision. ${ }^{2}$ Further, we test whether variable rate loans were merely a reaction to high and volatile interest rates in the late 1970s and early 1980s, and have since lost appeal. ${ }^{3}$

\subsection{Business Loan Data and Hypotheses}

The issue of choice between fixed and variable rate loans is relevant only to long-term loans. In this analysis, we therefore consider price and volume data on long-term business loans from the first quarter of 1977 to the second quarter of 1996, obtained from the Survey of Terms of Bank Lending. ${ }^{4}$ The data comprises all loans made by a sample of 292 "small" and 48 "large" commercial banks during the first full business week in the mid-month of each quarter. The assets of "large" banks were at least seven billion dollars as on September 30, 1990. Other banks are categorized as "small" banks. The loans are classified as "short-term" if the stated maturity was less than one year and "long-term" otherwise. Loans are classified as "fixed-rate" if the rate applicable for the entire period was known with certainty and "variable-rate" otherwise. The four loan size classifications for long-term loans are \$1-99 thousand, \$100-499 thousand, \$500-999 thousand and \$1 million + . The survey reports the weighted average characteristics of loans extended in each period for each loan type. The average values reported in the survey represent the characteristics of a "representative" loan of a particular loan type. ${ }^{5}$

We model the choice decision using seventy-eight time-series observations for each of eight cross sections (the eight cross-sections correspond to four loan sizes for each of two bank sizes). One of the significant shortcomings of earlier studies of the mortgage choice decision was that while the rate on the type of loan selected was observable, the rate on the loan type not selected was not known. Both fixed and variable rates on loans with similar characteristics and at a point in time could not be observed directly, and hence had to be estimated. The use of the STBL business loan rate indices provides direct observations on both fixed and variable loan rates simultaneously and avoids the problem encountered by Brueckner and Follain (1988).

The dependent variable (VARVOL) used in this analysis is the proportion of dollar volume of variable rate loans to the dollar volume of total (fixed + variable) loan extensions, by each loan size and bank type category. The dependent variable therefore represents a continuous index of preferences for the variable rate loan. ${ }^{6}$

The explanatory variables used in this analysis to explain the proportion of variable rate loans are those generally found significant in studies of the mortgage choice decision (Brueckner and Follain (1988), and Goldberg and Heuson (1992)). These variables include the level of interest rates as represented by the level of the prime rate (PRIME) and the difference in interest rates on fixed rate and variable rate loans (DRATE). Based on extant mortgage choice literature, we expect the coefficient on PRIME and DRATE to be positive. ${ }^{7}$ When DRATE is positive and large, fixed rate loans are relatively more expensive, causing borrowers to select variable rate loans. Expectations of future short-term interest rates, imbedded in the slope of the term structure, are proxied by the difference between the ten-year and one-year constant maturity rates on Treasury securities. A steep yield curve is indicative of rising short-term interest rates, hence we expect borrowers to avoid variable rate loans, and the coefficient on TERM is expected to be negative. ${ }^{8}$ While future values of the prime rate are unknown, we calculate the historic variance of the prime rate (VARPR) using the current and eight prior quarter values of the prime rate. The prevailing level of default risk (RISK) is proxied by the difference between the yield on Moody's BAA and AAA rated bonds. ${ }^{9}$ During periods of economic stability we would expect a propensity to variable rate loans, and hence the coefficients on both VARPR and RISK are expected to be negative. DMAT is the difference between the average maturity on fixed and variable rate loans. Borrowers prefer fixed rate contracts for longer maturity contracts and hence the coefficient on DMAT is expected to be negative.

Large banks and small banks operate under differing sets of constraints, economies and risk tolerance, which may influence their respective preferences for fixed or variable rate loans. Therefore, other control variables used in the analysis are dummy variables for the interaction of each bank size with the largest loan size classification. SBS4 is the interaction of a small bank dummy ( $\mathrm{SB}=1$ if the data pertains to a small bank) with the largest loan size dummy ( $\mathrm{S} 4=1$ if the loan size category is $\$ 1+$ million) and represents large loans at small banks. 
Similarly, LBS4 is the interaction of a large bank dummy (LB = 1 if the data pertains to a large bank) with the largest loan size dummy (S4) and represents large loans at large banks. The bank size and loan size interaction proxies for the differential loan choice decisions based on lender size and borrower size. These variables should equal zero if bank size and loan size does not influence the choice decision.

The data used in this analysis can be separated into two distinct sub-periods: the twenty-four quarters from 1977.1 to 1982.4, and the period after the high and volatile interest rates covering fifty-four quarters from 1983.1 to 1996.2. The influence of the two sub-periods is characterized by an interaction of the sub-period dummy, a trend variable and the bank size dummies, i.e. PRE82S is the interaction of the first sub-period (PRE82 = 1 between 1977.1 and 1982.4), the small bank dummy (SB) and the influence of time (TREND $=0.25$ at 1977.1 and is incremented by 0.25 at each quarter). POS82S is the interaction of the second sub-period (POS82 $=1$ between 1993.1 and 1996.2), the small bank dummy, and the trend variable. PRE82L is the interaction of the first sub-period, the large bank dummy (LB), and the trend variable. POS82L is the interaction of the second sub-period, the large bank dummy and the trend variable. While banks were generally allowed to extend variable rate mortgage loans from 1981, they did extend variable rate business loans prior to 1981. If the propensity to variable rate loans can be explained by other variables, the coefficient of these variables (viz. PRE82S, POS82S, PRE82L, and POS82L) should be zero.

Sample statistics for the dependent and explanatory variables used in this analysis are presented in Table 1.

Table 1: Sample statistics for the dependent and explanatory variables

The dependent variable (VARVOL) represents a continuous index of preferences for the variable rate loan, covering seventy-eight quarters from the first quarter of 1977 to the second quarter of 1996, and eight cross-sections comprising four loan sizes at large and small banks.

\begin{tabular}{|c|c|c|c|c|}
\hline Variable & Mean & Std. Dev. & Min. & Max. \\
\hline $\begin{array}{l}\text { VARVOL } \\
\text { The proportion of variable rate loan volume to total }\end{array}$ & 17.07 & 19.12 & 0.76 & 82.51 \\
\hline $\begin{array}{l}\text { PRIME }(+) \\
\text { The level of the prime rate }\end{array}$ & 10.13 & 3.42 & 6.00 & 20.50 \\
\hline $\begin{array}{l}\text { DRATE }(+) \\
\text { Fixed less variable interest rate }\end{array}$ & -0.43 & 1.47 & -10.03 & 4.55 \\
\hline $\begin{array}{l}\text { TERM (-) } \\
\text { Slope of the term structure }\end{array}$ & 1.04 & 1.23 & -2.10 & 3.20 \\
\hline $\begin{array}{l}\text { VARPR (-) } \\
\text { Variance of the prime }\end{array}$ & 3.04 & 3.56 & 0.04 & 13.05 \\
\hline $\begin{array}{l}\text { RISK (-) } \\
\text { Yield on BAA less AAA bonds }\end{array}$ & 1.17 & 0.47 & 0.55 & 2.62 \\
\hline $\begin{array}{l}\text { DMAT (-) } \\
\text { Average fixed less variable maturity }\end{array}$ & 7.98 & 17.78 & -72.00 & 113.00 \\
\hline $\begin{array}{l}\text { SBS4 }(0) \\
\text { Interaction of small bank and largest loan size dummy }\end{array}$ & 0.13 & 0.33 & 0 & 1 \\
\hline $\begin{array}{l}\text { LBS4 (0) } \\
\text { Interaction of large bank and largest loan size dummy }\end{array}$ & 0.13 & 0.33 & 0 & 1 \\
\hline $\begin{array}{l}\text { PRE82S (0) } \\
\text { Interaction of first sub-period, small bank and trend }\end{array}$ & 0.48 & 1.32 & 0 & 6 \\
\hline $\begin{array}{l}\text { POST82S }(0) \\
\text { Interaction of second sub-period, small bank and trend }\end{array}$ & 4.46 & 6.54 & 0 & 19.5 \\
\hline $\begin{array}{l}\text { PRE82L }(0) \\
\text { Interaction of first sub-period, large bank and trend }\end{array}$ & 0.48 & 1.32 & 0 & 6 \\
\hline $\begin{array}{l}\text { POST82L }(0) \\
\text { Interaction of second sub-period, large bank and trend }\end{array}$ & 4.46 & 6.54 & 0 & 19.5 \\
\hline
\end{tabular}




\subsection{The Estimation Process}

Since we utilize time series and cross sectional data, we chose the single equation Parks (1967) method ${ }^{10}$ to estimate the coefficients of the model, generally specified as-

$$
Y_{i t}=\sum_{k=1}^{K} X_{i t k} \beta_{k}+\varepsilon_{i t}
$$

where, $Y$ represents a vector of the dependent variable as described earlier, $X$ represents a non-stochastic matrix of independent variables as described earlier, $\beta$ represents a vector of estimated coefficients, $i$ represents the cross sectional observations, $t$ represents the length of the time series, k represents the number of independent variables, and $\varepsilon$ represents a vector of error terms. The estimator is efficient, consistent and has the same asymptotic properties as Aitken's GLS estimator. We assume a first order autoregressive model with contemporaneous correlation between cross sections. The single equation can also be interpreted as the reduced form of borrower and lender preferences where the coefficients of the reduced form equation depend on whether the borrower or lender preference dominates. The estimates of the coefficients of the model are presented in Table 2.

\section{Table 2: Regression Results for the commercial loan fixed or variable rate choice model}

The model tests variables suggested by theory or those generally found to be significant in previous studies of the fixed and variable loan choice decision (PRIME, DRATE, TERM, VARPR, RISK, and DMAT). Additional test variables used to explain the loan choice decision include interaction variables for lender and borrower size (SBS4, LBS4) and dummy variables for preference shifts between regimes (PRE82S, POST82S, PRE82L, and POST82L). The dependent variable is the ratio of variable rate loans to total loans in each category (multiplied by 100 for ease in presentation and interpretation) and represents a continuous index of preferences for the variable rate commercial loan.

\begin{tabular}{lc}
\multicolumn{1}{c}{ Variable } & Estimate of \\
& Coefficient \\
& \\
\hline INTERCEPT & -0.18 \\
& $(-0.11)$ \\
PRIME & 0.13 \\
The level of interest rates & $(0.82)$ \\
DRATE & 0.13 \\
Fixed less variable interest rate & $(1.04)$ \\
TERM & -0.50 \\
10 year less 1 year constant maturity rates & $(-1.49)$ \\
VARPR & 0.14 \\
Variance of the prime rate & $(1.18)$ \\
RISK & $2.61^{* *}$ \\
Yields on BAA less AAA rated bonds & $(2.79)$ \\
DMAT & 0.00 \\
Average fixed less variable maturity & $(0.20)$ \\
SBS4 & $20.43^{* *}$ \\
Interaction of small bank and largest loan size dummy & $(15.75)$ \\
LBS4 & $53.76^{* *}$ \\
Interaction of large bank and largest loan size dummy & $(38.54)$ \\
PRE82S & -0.05 \\
Interaction of first sub-period, small bank and trend & $(-0.15)$ \\
POST82S & $0.59^{* *}$ \\
Interaction of second sub-period, small bank and trend & $(7.27)$ \\
PRE82L & 0.03 \\
Interaction of first sub-period, large bank and trend & $(0.12)$ \\
POST82L & $0.32^{* *}$ \\
Interaction of second sub-period, large bank and trend & $(3.80)$ \\
\hline Regression Diagnostics for the Parks Single Equation Estimation Method & \\
Number of Cross Sections & 8 \\
Time Series Length & 78 \\
DFE & 611 \\
R-Square & $74 \%$ \\
** Significant at the 1\% level. The t-statistic is placed below the coefficient in parentheses. \\
\end{tabular}


We assume an autoregressive process of order one with contemporaneous correlation among the crosssections. See Parks (1967) for details of the single equation estimation method.

The coefficients on the level of interest rates (PRIME), the spread between the fixed and variable rate (DRATE), the term structure (TERM), the variance of the prime rate (VARPR), and the maturity differences between fixed and variable rate loans (DMAT) are insignificant. The inclusion of these variables was suggested by theoretical models and was consistent with previous empirical studies using mortgage loan data. ${ }^{11}$ However, none were found to be significant determinants of the business loan choice decision. A surprising observation is that the RISK variable is positive and significant - implying that at higher levels of concurrent economic risk there is a greater likelihood of variable rate contracts.

The small bank and large loan interaction dummy variable (SBS4) is positive and highly significant as is the large bank and large loan interaction dummy variable (LBS4), indicating that large loans are generally variable rate loans. These results indicate a clear segmentation within the market for variable rate loans. Long-term loans of more than $\$ 1$ million increase the likelihood of a given loan being variable by about 20 percent in the case of small banks and by about 53 percent in the case of large banks. The larger loan sizes show a greater likelihood of variable rates as compared to smaller loan sizes, and large banks show a greater propensity for variable rate loans as compared to smaller banks. This result is consistent with the notion that larger banks and larger borrowers may have a greater ability to manage risk and hence a greater propensity toward variable rate loans, and is also consistent with the Booth and Chua (1995) assertion that virtually all large loans are at variable rate.

The trend variables PRE82S and PRE82L are insignificant. However, both POST82S and POST82L are positive and significant, indicating that the trend towards variable rate loans is continuing even after the period of high and volatile interest rates experienced in the late 1970s and early 1980s.

\subsection{Conclusions and Suggestions for Future Research}

The choice between fixed and variable rate business loans is clearly different from the choice between fixed and variable rate mortgage loans. Differences in maturity, size, repayment terms, collateral, secondary markets and securitization; are probably only some of the factors that may influence the determination of the business loan choice decision relative to the mortgage loan choice decision.

We have shown that the determinants of the business loan choice decision are not the same as the mortgage loan choice decision. By introducing interaction dummy variables for bank size and loan size we have shown that the business loan choice decision is also segmented by bank size and loan size. ${ }^{12}$ Finally, we have also shown that the propensity for variable rate business loans has been increasing even after the period of high and volatile interest rates.

Business managers need to analyze the choice of variable rate loans as part of the general problem of the optimal capital structure of the firm, while bank managers need to analyze the choice of variable rate loans as part of the general problem of optimal portfolio allocation. Given the greater preference of large banks for variable rate loans, consolidation among banks creates a secular trend to variable rate loans which poses a significant risk for businesses with asset returns uncorrelated with short-term loan rates. While some businesses may have the capability to bear the uncertainty resulting from interest rate risk, others need to use hedging tools to immunize rate risk. These business borrowers, aware of the risk induced by variable rate loan terms, are a developing market for derivative hedging products that improve corporate financial management.

Additional research is needed to examine firm specific choice decisions and determine the interactions of the firm's operating and financing characteristics, hedging activities, and other economic variables, on the firm specific choice decision. 


\section{Endnotes}

1. Cox, Ingersoll and Ross (1980).

2. Modigliani and Sutch (1956) considered the existence of "preferred habitats", and Culbertson (1957) considered the existence of "market segmentation" in financial markets.

3. See Brueckner and Follain (1988) for a discussion of the relative importance of the variable rate mortgage loans in the 1980s.

4. A quarterly statistical release of the Board of Governors of the Federal Reserve System.

5. The Federal Reserve does not make data on individual loan transactions publicly available. The loan rate indices used here provide a continuous time series of loan rates and eliminate discontinuities in loan rates.

6. An increase in the dependent variable can be interpreted as an increase in preference for the variable rate loans relative to fixed rate loans.

7. The sign depends on both borrower and lender preferences - and the dominance of one over the other is an empirical issue. The hypothesized relationship shown here is for expositional purpose only, and is from the borrower's perspective.

8. Obtained from the Federal Reserve Bulletin. According to Cox, Ingersoll and Ross (1985) "The term structure embodies the markets anticipation of future events".

9. $\quad$ Obtained from the Federal Reserve Bulletin.

10. This method is useful in the analysis of panel data, is available on SAS as an ETS procedure, and has recently been used by Brockman and Chung (1999), Shyam-Sunder and Myers (1999), Dewan and Kraemer (2000), and Durham (2001), to test hypotheses and in tests of robustness.

11. We also used the McFadden multinomial logit specification for the independent variable. The interpretation of those results is similar to the results presented, which indicates that the results are not dependent on specification.

12. These results can be contrasted to Fugitte (1984, p.22) who states, "There are two major problems with variable rate lending. First, nobody wants it, and second, it's not in the consumer's interest".

\section{References}

1. Agmon, T., A. R. Ofer and A. Tamir, 1981, Variable rate debt instruments and corporate debt policy, The Journal of Finance 36, 113-125.

2. Baesel, Jerome B. and Nahum Biger, 1980, The allocation of risk: Some implications of fixed versus indexlinked mortgages, Journal of Financial and Quantitative Analysis 15, 457-468.

3. Balsam, S. and Sungsoo Kim, 2001, Effects of interest rate swaps, Journal of Economics and Business 53, 547-562.

4. Berkovec, James A., David J. Kogut and Frank E. Nothaft, 2001, Determinants of the ARM share of FHA and conventional lending, Journal of Real Estate Finance and Economics 22, 23-41.

5. Booth, James R. and Lena Chua, 1995, Structure and pricing of large bank loans, Federal Reserve Bank of San Francisco Economic Review, 52-62.

6. Brewer, Elijah, William E. Jackson and Thomas S. Mondschean, 1996, Risk, Regulation, and S\&L diversification into nontraditional assets, Journal of Banking and Finance 20, 723-744.

7. Brockman, Paul and Dennis Y. Chung, 1999, An analysis of depth behavior in an electronic, order-driven environment, Journal of Banking and Finance 23, 1861-1886.

8. Brueckner, Jan K. and James R. Follain, 1988, The rise and fall of the ARM: An econometric evaluation of mortgage choice, The Review of Economics and Statistics 70, 93-101.

9. Calhoun, Charles A. and Yongheng Deng, 2002, A dynamic analysis of fixed- and adjustable-rate mortgage terminations, Journal of Real Estate Finance and Economics 24, 9-33.

10. Chang, Eric, Moon-Whoan Rhee and Kit Pong Wong, 1995, A note on the spread between the rates of fixed and variable rate loans, Journal of Banking and Finance 19, 1479-1487.

11. Cox, John C., Jonathan E. Ingersoll and Stephen A. Ross, 1980, An analysis of variable rate loan contracts, The Journal of Finance 35, 389-403.

12. Cox, John C., Jonathan E. Ingersoll and Stephen A. Ross, 1985, A theory of the term structure of interest rates, Econometrica 53, 385-407. 
13. Culbertson J. M, 1957, The term structure of interest rates, Quarterly Journal of Economics 71, 485-517.

14. Cunningham, Donald F. and Charles A. Capone Jr., 1990, The relative termination experience of adjustable to fixed-rate mortgages, The Journal of Finance 45, 1687-1703.

15. Dewan, Sanjeev and Kenneth L. Kraemer, 2000, Information technology and productivity: Evidence from country level data, Management Science 46, 548-562.

16. Dhillon, Upinder S., James D. Shilling and C.F. Sirmans, 1987, Choosing between fixed and variable rate mortgages, Journal of Money, Credit and Banking 19, 260-267.

17. Dhillon, Upinder S., J. Sa-Aadu and James D. Shilling, 1996, Choosing between fixed- and adjustable rate mortgages: The case of commercial mortgages, Journal of Real Estate Finance and Economics 12, 265277.

18. Durham, J. Benson, 2001, Sensitivity analysis of anomalies in developed stock markets, Journal of Banking and Finance 25, 1503-1541.

19. Fugitte, James, 1984, Borrowers do not need or want variable rate loan, American Banker 149, 22.

20. Goldberg, Lawrence G. and Andrea J Heuson, 1992, Fixed versus variable rate financing: The influence of borrower, lender, and market characteristics, Journal of Financial Services Research 6, 49-60.

21. Hendershott, P. and R. Van Order, 1987, Pricing mortgages: An interpretation of the models and results, Journal of Financial Services Research 1, 77-111.

22. Modigliani, F. and R. J. Sutch, 1956, Innovations in interest rate policy, American Economic Review 56, 178-197.

23. Parks, R.W., 1967, Efficient estimation of a system of regression equations when disturbances are both serially and contemporaneously Correlated, Journal of The American Statistical Association 62, 500-509.

24. Page, Daniel E. and C. F. Sirmans, 1984, Yield differences on fixed and variable rate mortgages, Quarterly Review of Economics and Business 24, 18-28.

25. Sa-Aadu, J. and C. F. Sirmans, 1995, Differentiated contracts, heterogeneous borrowers, and the mortgage choice decision, Journal of Money, Credit and Banking 27, 498-510.

26. Santomero, Anthony M., 1983, Fixed versus variable rate loans, The Journal of Finance 38, 1363-1380.

27. SAS Institute Inc., SAS/ETS Users Guide v.6 second edition, Cary, NC.

28. Shyam-Sunder, Lakshmi and Stewart C. Myers, 1999, Testing static tradeoff against pecking order models of capital structure, Journal of Financial Economics 51, 219-244.

29. Smith, Donald J., 1987, The borrower's choice between fixed and variable rate loan contracts, AREUEA Journal 15, 110-116.

30. Stango, Victor, 2000, Competition and pricing in the credit card market, Review of Economics and Statistics 82, 499-508.

31. Tucker, Michael, 1991, Comparing present value cost differentials between fixed and variable rate loans: A mortgage simulation, The Financial Review 26, 447-458. 